\title{
Toxicological evaluation of flumequine in pubertal male rats after oral administration for six weeks
}

\author{
JeongWoo Kang ${ }^{1}$, Md Akil Hossain ${ }^{1}$, Byungkook Choi ${ }^{1}$, \\ Joon-Hyoung Cho ${ }^{1}$, Seok-Jin Kang ${ }^{1}$, Hyun-Ok Ku${ }^{1}$, \\ Sang-Hee Jeong ${ }^{2}$, Hwan-Goo Kang ${ }^{1}$ \\ ${ }^{1}$ Veterinary Drugs and Biologics Division, Animal and Plant Quarantine Agency, \\ 177, Hyeoksin 8-ro, Gimcheon-si, Gyeongsangbuk-do 39660, Republic of Korea \\ ${ }^{2}$ GLP Research Center, College of Natural Sciences, \\ Hoseo University, 165, Asan City, Republic of Korea \\ kanghg67@korea.kr
}

Received: August 03, $2017 \quad$ Accepted: February 20, 2018

\begin{abstract}
Introduction: Veterinarians use flumequine (FLU) widely but its toxicological effects are still unclear. Material and Methods: FLU doses of 53, 200, or $750 \mathrm{mg} / \mathrm{kg}$ were administered orally for six weeks to pubertal male rats for evaluation of their toxicity. Results: Weight gain was poorer after seven days of exposure to FLU 750, but relative weights of the brain, adrenal and thyroid glands, and testes were notably higher. Haematological and lipid profile parameters, cardiac markers, and inorganic phosphate significantly increased in the FLU 750 group. Blood glucose, oestradiol and serum concentrations of immunoglobulins G (IgG) and E (IgE) significantly decreased after treatment. The levels of interleukins 10 (IL-10) and 6 (IL-6) fell significantly in the FLU 200 and FLU 750 groups. Cytochrome P450, family 1, subfamily A, polypeptide 1 (CYP1A1) and cyclooxygenase-2 (Cox-2) expression amplified after treatment. Serum levels of free triiodothyronine (fT3) and free thyroxine (fT4) reduced in the FLU 200 and FLU 750 groups without changes in total T3 or T4 level. All doses of FLU significantly depressed concentrations of thyroid-stimulating hormone (TSH) and testosterone. Histopathology of thyroid glands from rats treated with FLU 750 showed degeneration and depletion of thyroid follicular epithelial cells. Expression of 8-hydroxydeoxyguanosine $(8-\mathrm{OHdG})$ was increased in a dose-dependent manner in the brain, but decreased in the testes. Expression of CYP1A1 increased in the adrenal and pituitary glands. Conclusion: The results of this study suggest that the toxicity of FLU in rats is an effect of its disruptive influence on the pituitary-thyroid hormonal system and on the dysfunction of the immune system.
\end{abstract}

Keywords: male rats, flumequine, toxicity, pituitary gland, thyroid gland.

\section{Introduction}

Flumequine (FLU) is a first-generation quinolone antibacterial agent which has been used in veterinary medicine against a wide range of Gram-negative bacterial infections (1). Flumequine is used in humans at a dose of 1,200 mg/day divided into three doses. In a pharmacovigilance study carried out from 1984 to 1993, the following incidences of side effects were reported: allergy and digestive, neurological, and neuro-sensorial effects (19). On the other hand, FLU showed positive immunological effects by enhancing proliferation of lymphoid cells, especially surface immunoglobulin negative cells in eels (20). FLU accelerated the glutamic-pyruvate transaminase (GPT) and Spi(-) mutant frequencies induced by 2-amino-3,8dimethylimidazo(4,5-f) quinoxaline (MeIQx) in the mouse liver by increasing cytochrome P450 1a2 (CYP1A2) mRNA levels and decreasing UDP glucuronosyltransferase 1 family, polypeptide B1 (UGT1B1) mRNA levels (13).

However, there are controversial reports regarding the carcinogenicity of FLU since no carcinogenic effects were observed in rats, but liver tumours were observed in CD-1 mice after oral exposure for 18 months (21). Acute oral and parenteral toxicity studies 
in various animal species including mice, rats, rabbits, and dogs showed that FLU has low toxicity. Lethal dose $50 \%\left(\mathrm{LD}_{50}\right)$ values exceed $1 \mathrm{~g} / \mathrm{kg}$ body weight. Subacute toxicity tests involving repeated administration over two to three weeks confirm this low toxicity (19). The Food and Agriculture Organization of the United Nations (FAO), World Health Organization (WHO), and Joint Expert Committee on Food Additives (JECFA) concluded that FLU is a non-genotoxic hepatocarcinogen (11).

Although some articles have been published describing the toxicological effects of FLU on different animals, they are not sufficient to build a clear-cut toxicological profile of FLU. Moreover, no toxicity study of FLU on the hormonal system has been reported yet. Thus, in the current study we intended to evaluate the toxicological effects of FLU on the endocrine system in rats together with the effect on the immunological system.

\section{Material and Methods}

Animals. Pubertal male Wistar rats (aged 21 days) were purchased from Charles River (Atsugi, Japan). A commercial diet ( $\sigma$-irradiated, Purina Laboratory Mouse Chow, Republic of Korea) and tap water were provided ad libitum. The animal room was maintained at a temperature of $24 \pm 2^{\circ} \mathrm{C}$ with a relative humidity of $50 \pm 20 \%$, and a $12 \mathrm{~h}$ light/dark cycle. The rats were divided into four groups with seven animals per group (2-3 rats $/ 30 \mathrm{~cm} \times 60 \mathrm{~cm} \times 30 \mathrm{~cm}$ cage). Allocation to groups was by body weight randomisation to ensure equal weight distribution among the groups. All animals were handled according to the Code of Laboratory Animal Welfare and Ethics of the Animal and Plant Quarantine Agency, Republic of Korea.

Chemicals and treatment. The animal experimental protocol, dosage design, and study time were established with due consideration of the protocol in OECD guidelines (15). FLU (Sigma-Aldrich, Republic of Korea) was dissolved in corn oil, and administered orally daily at 53,200 , and $750 \mathrm{mg} / \mathrm{kg}$ b.w. (FLU 53, FLU 200, and FLU 750 groups) for six weeks. Pure corn oil was given to the control group. Body weight and feed and water consumption were measured daily. Approximately $24 \mathrm{~h}$ after the last treatment, blood samples were collected from the jugular vein without anaesthesia, according to the protocol of Cho et al. (4). The animals were then euthanised by cervical dislocation, and the brain, thymus, thyroid and adrenal glands, lungs, liver, kidneys, testes, epididymis, and prostate glands were collected. Serum and tissue samples were stored at $-80^{\circ} \mathrm{C}$ until analysis. Haematological and serum biochemical parameters were measured with a Hemavet 950 haematology system (Drew Scientific, USA) and an Olympus AU400 auto analyser (Olympus, USA), respectively.
Determination of hormones, immunoglobulins, and cytokines. Total thyroxine (tT4), free thyroxine (fT4), total triiodothyronine (tT3), free triiodothyronine (fT3), oestradiol, and testosterone were determined using commercially available DELFIA kits (PerkinElmer, USA) according to the manufacturer's instructions. Luteinising hormone (LH), thyroidstimulating hormone (TSH), and follicle-stimulating hormone (FSH) were measured by radioimmunoassay (RIA) using Amersham RIA kits (GE healthcare, UK) according to the manufacturer's protocols. Hormone concentrations were measured using a Packard D5005 Cobra II automatic gamma counter (Packard Bioscience, now part of PerkinElmer, USA) according to the manufacturer's instructions.

The levels of immunoglobulin A ( $\operatorname{IgA}), \mathrm{G}(\operatorname{IgG})$, $\mathrm{M}(\operatorname{IgM})$, and $\mathrm{E}(\mathrm{IgE})$ were measured with ELISA kits (Bethyl Laboratories, USA) according to the supplier's instructions. Absorbance was measured at $450 \mathrm{~nm}$ using a SpectraMax plus microplate reader (Molecular Devices, USA). Serum concentrations of interleukin-10 (IL-10), interleukin-6 (IL-6), tumour necrosis factor- $\alpha$ (TNF $\alpha$ ), interferon- $\gamma$ (IFN- $\gamma$ ), granulocyte-macrophage colony-stimulating factor (GM-CSF), interleukin-1 $\beta$ (IL-1 $\beta$ ), and interleukin-2 (IL-2) were determined with a Bio-plex rat cytokine-9-plex A panel (Bio-Rad, USA).

Preputial separation and sperm analysis. Preputial separation times were monitored daily from the start of treatment with FLU. The right and left cauda epididymides were used for sperm count and motility. Both motility and sperm count were measured by computer aided sperm analysis imaging system (SAIS 351 software v. 10.1, Medical Supply Company, Republic of Korea) after sample preparation according to Jeong et al. (10).

Histopathological examination. Histopathological studies were performed according to Groelz et al. (8). The collected organs were fixed in a $10 \%$ neutral buffered formalin. Paraffin sections were cut to $2 \mu \mathrm{m}$ preparations stained with Ehrlich's haematoxylin and eosin and examined under light microscope.

Tissue microarray-immunohistochemistry assay. A tissue block containing six different tissues representing six organs (liver, brain, spleen, adrenal glands, pituitary gland, and testes) from all rats was made using a Chemicon ATA-100 tissue arrayer (Chemicon, USA). The expression of 8-hydroxydeoxyguanosine (8-OHdG), cytochrome P450, family 1, subfamily A, polypeptide 1 (CYP1A1), IL-1 $\beta$, and cyclooxygenase-2 (Cox-2) was examined immunohistochemically according to the manufacturer's instructions. Briefly, an indirect avidin-biotin complex $(\mathrm{ABC})$ immuno-peroxidase assay was performed using a commercially available Dako ABC kit (Dako, USA). Sections were incubated with non-immune rabbit serum at 1:100 dilution in Tris-buffered saline $(\mathrm{pH}$ 7.6) for $30 \mathrm{~min}$, and after washing with Tris-buffered saline, incubated with each primary antibody. To block 
endogenous peroxidase activity, the sections were subsequently incubated with $3 \%$ hydrogen peroxide in methanol for $30 \mathrm{~min}$. Following incubation with biotinylated rabbit anti-mouse antibody for $1 \mathrm{~h}$, the immunoenzymatic reaction was developed using 3,3'-diaminobenzidine as the chromogenic substrate. After extensive washing, nuclear counterstaining was achieved using Mayer's haematoxylin. The immunohistochemical expressions of each protein were analysed with the iSolution DT image analysis programme (IMT i-Solution, USA).

Statistical analysis. The results are represented as the mean \pm standard deviation from seven individual determinations. Statistical significance was determined using Statistica version 5.5 (Statsoft, USA). One-way analysis of variance was performed with post hoc comparisons between the vehicle control group and each treatment group by Duncan's multiple comparison tests.

\section{Results}

Body and organ weights. Weight gain after seven days' treatment with $750 \mathrm{mg} / \mathrm{kg}$ of FLU was significantly weaker compared with control rats and remained lower throughout the treatment period (Fig. 1). Relative weights of the brain, thyroid, adrenal glands, and testes were significantly $(\mathrm{P}<0.01$, $\mathrm{P}<0.05$ ) greater in the FLU 750 group (Fig. 2). The relative weights of the thyroid glands in the FLU 200 and FLU 750 groups significantly $(\mathrm{P}<0.01, \mathrm{P}<0.05$,

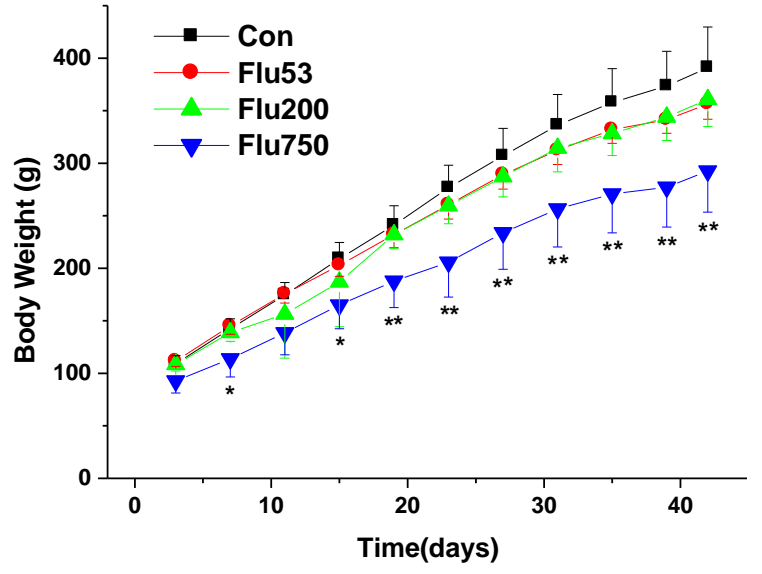

Fig. 1. Body weight changes in pubertal male Wistar rats treated with corn oil (control) or with flumequine (FLU) at doses of 53, 200 and $750 \mathrm{mg} / \mathrm{kg}$ for six weeks. Values are mean \pm SD for seven rats in each group. $* \mathrm{P}<0.05, * * \mathrm{P}<0.01$

respectively) exceeded those of the control group (Fig. 2).

Haematology and serum biochemistry. The white blood cell (WBC) and monocyte (MO) counts, corpuscular haemoglobin $(\mathrm{CH})$, and mean corpuscular haemoglobin $(\mathrm{MCH})$ significantly $(\mathrm{P}<0.05$ or $\mathrm{P}<0.01)$ increased in the FLU 750 group compared to corresponding values in the controls (Table 1). Serum activities of creatine kinase (CK) and lactate dehydrogenase $(\mathrm{LDH})$ significantly $(\mathrm{P}<0.05)$ intensified and blood glucose concentration significantly diminished $(\mathrm{P}<0.01)$ in the FLU 750 group compared to the corresponding levels in the control group (Table 2).
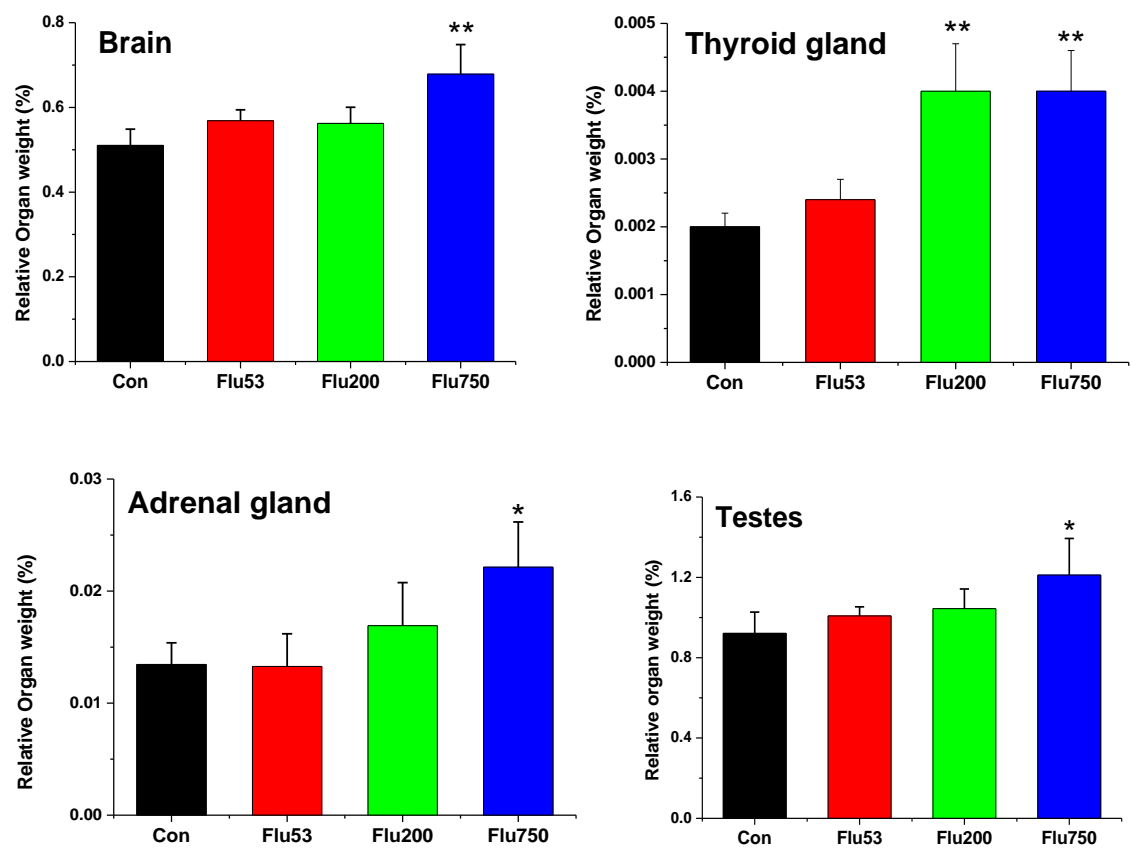

Fig. 2. Relative organ weights in pubertal male Wistar rats treated with corn oil (control) or with flumequine (FLU) at doses of 53, 200 and $750 \mathrm{mg} / \mathrm{kg}$ for six weeks. Values are mean $\pm \mathrm{SD}$ for seven rats per treatment group. $* \mathrm{P}<0.05, * * \mathrm{P}<0.01$ 
Table 1. Haematological parameters of male Wistar rats exposed to FLU for six weeks

\begin{tabular}{|c|c|c|c|c|}
\hline Parameters & Control & $53 \mathrm{mg} / \mathrm{kg}$ & $200 \mathrm{mg} / \mathrm{kg}$ & $750 \mathrm{mg} / \mathrm{kg}$ \\
\hline $\mathrm{RBC}\left(\times 10^{6}\right.$ cells $\left./ \mathrm{mL}\right)$ & $7.58 \pm 0.2$ & $7.43 \pm 0.31$ & $6.72 \pm 1.24$ & $7.07 \pm 0.31$ \\
\hline HGB (g/dL) & $13.9 \pm 0.50$ & $13.9 \pm 0.59$ & $12.62 \pm 2.35$ & $13.5 \pm 0.49$ \\
\hline $\operatorname{HCT}(\%)$ & $41.6 \pm 2.10$ & $41.5 \pm 1.55$ & $38.1 \pm 8.1$ & $41.2 \pm 1.23$ \\
\hline MCV (fL) & $54.73 \pm 1.64$ & $55.9 \pm 1.63$ & $56.32 \pm 2.12$ & $58.8 \pm 0.4$ \\
\hline $\mathrm{MCH}(\mathrm{pg})$ & $18.3 \pm 0.43$ & $18.7 \pm 0.39$ & $18.72 \pm 0.13$ & $19.1 \pm 0.32 *$ \\
\hline $\mathrm{MCHC}(\mathrm{g} / \mathrm{dL})$ & $33.43 \pm 0.4$ & $33.5 \pm 0.76$ & $33.3 \pm 1.07$ & $32.8 \pm 0.34$ \\
\hline $\mathrm{CHCM}(\mathrm{g} / \mathrm{dL})$ & $33.64 \pm 0.52$ & $34 \pm 0.96$ & $33.61 \pm 0.86$ & $33.3 \pm 0.93$ \\
\hline $\mathrm{CH}(\mathrm{pg})$ & $18.4 \pm 0.5$ & $19 \pm 0.38$ & $18.88 \pm 0.51$ & $19.4 \pm 0.55^{* *}$ \\
\hline RDW (\%) & $11.4 \pm 0.43$ & $11.5 \pm 0.5$ & $11.34 \pm 0.64$ & $12 \pm 0.45$ \\
\hline HDW (g/dL) & $2.40 \pm 0.08$ & $2.48 \pm 0.18$ & $2.30 \pm 0.14$ & $2.42 \pm 0.15$ \\
\hline PLT $\left(\times 10^{3}\right.$ cells $\left./ \mathrm{mL}\right)$ & $1315 \pm 271$ & $1264 \pm 223$ & $737.4 \pm 655$ & $1356 \pm 81.23$ \\
\hline MPV (fL) & $7.17 \pm 0.28$ & $7.13 \pm 0.27$ & $10 \pm 4.77$ & $7.36 \pm 0.15$ \\
\hline WBC $\left(\times 10^{3}\right.$ cells $\left./ \mathrm{mL}\right)$ & $5.75 \pm 1.34$ & $5.75 \pm 2.41$ & $6.91 \pm 3.9$ & $9.21 \pm 2.49 *$ \\
\hline $\mathrm{NE}\left(\times 10^{3}\right.$ cells $\left./ \mathrm{mL}\right)$ & $16.39 \pm 2.92$ & $18.4 \pm 3.95$ & $15.82 \pm 3.29$ & $19.2 \pm 3.92$ \\
\hline $\mathrm{LY}\left(\times 10^{3}\right.$ cells $\left./ \mathrm{mL}\right)$ & $79.59 \pm 3.18$ & $77.3 \pm 4.04$ & $80.3 \pm 3.23$ & $75.7 \pm 4.87$ \\
\hline $\mathrm{MO}\left(\times 10^{3}\right.$ cells $\left./ \mathrm{mL}\right)$ & $1.32 \pm 0.39$ & $1.53 \pm 0.37$ & $1.72 \pm 0.68$ & $2.34 \pm 1.07 *$ \\
\hline $\mathrm{EO}\left(\times 10^{3}\right.$ cells $\left./ \mathrm{mL}\right)$ & $1.72 \pm 0.63$ & $1.77 \pm 0.65$ & $1.34 \pm 0.89$ & $1.9 \pm 0.36$ \\
\hline $\mathrm{BA}\left(\times 10^{3}\right.$ cells $\left./ \mathrm{mL}\right)$ & $0.25 \pm 0.21$ & $0.29 \pm 0.16$ & $0.12 \pm 0.13$ & $0.2 \pm 0.07$ \\
\hline LUC $\left(\times 10^{3}\right.$ cells $\left./ \mathrm{mL}\right)$ & $0.65 \pm 0.39$ & $0.69 \pm 0.25$ & $2.16 \pm 3.27$ & $0.74 \pm 0.23$ \\
\hline
\end{tabular}

RBC - red blood cell; HGB - haemoglobin; HCT - haematocrit; MCV - mean corpuscular volume; MCH - mean corpuscular haemoglobin; $\mathrm{MCHC}$ - mean corpuscular haemoglobin concentration; $\mathrm{CHCM}$ - cellular haemoglobin concentration mean; $\mathrm{CH}$ corpuscular haemoglobin; RDW - red cell distribution width; HDW - haemoglobin distribution width; PLT - platelet count; MPV - mean platelet volume; WBC - white blood cell; NE - neutrophil; LY - lymphocyte count; MO - monocyte count; EO - eosinophil count; BA basophil count; LUC - large unstained cells. Values are mean $\pm \mathrm{SD}$ of seven rats in each group. $* \mathrm{P}<0.05 ; * * \mathrm{P}<0.01$

Table 2. Serum biochemical parameters of pubertal male Wistar rats exposed to FLU for six weeks

\begin{tabular}{|c|c|c|c|c|}
\hline Parameter & Control & $53 \mathrm{mg} / \mathrm{kg}$ & $200 \mathrm{mg} / \mathrm{kg}$ & $750 \mathrm{mg} / \mathrm{kg}$ \\
\hline $\operatorname{ALT}(\mathrm{U} / \mathrm{l})$ & $20.1 \pm 2.9$ & $19.8 \pm 3.7$ & $20.7 \pm 8.1$ & $24.3 \pm 7.6$ \\
\hline AST (U/l) & $61.2 \pm 6.4$ & $60.8 \pm 4.8$ & $65.6 \pm 5.6$ & $60.1 \pm 7.4$ \\
\hline $\operatorname{ALP}(\mathrm{U} / \mathrm{l})$ & $127.3 \pm 27.6$ & $140.8 \pm 35.7$ & $151.6 \pm 50.4$ & $141.1 \pm 37.8$ \\
\hline LDH (U/1) & $188.8 \pm 56.6$ & $264.9 \pm 110.4$ & $470.6 \pm 254.2 * *$ & $352.8 \pm 146.7 *$ \\
\hline CK (U/1) & $134.0 \pm 35.1$ & $162.4 \pm 57.3$ & $220.4 \pm 99.4$ & $326.0 \pm 194.1^{*}$ \\
\hline Alb (mg/dl) & $3.33 \pm 0.13$ & $3.27 \pm 0.12$ & $3.34 \pm 0.13$ & $3.30 \pm 0.13$ \\
\hline BUN (mg/dl) & $12.1 \pm 1.9$ & $12.8 \pm 1.4$ & $11.2 \pm 4.8$ & $11.9 \pm 3.3$ \\
\hline Glu (mg/dl) & $145.86 \pm 12.2$ & $145.5 \pm 15.4$ & $136.6 \pm 12.1$ & $109.7 \pm 13.5^{* *}$ \\
\hline $\mathrm{TG}(\mathrm{mg} / \mathrm{dl})$ & $92.2 \pm 32.9$ & $72.1 \pm 16.2$ & $74.3 \pm 20.2$ & $71.41 \pm 17.8$ \\
\hline $\mathrm{Ca}(\mathrm{mg} / \mathrm{dl})$ & $10.58 \pm 0.1$ & $10.23 \pm 0.4$ & $8.95 \pm 3.7$ & $10.38 \pm 0.5$ \\
\hline
\end{tabular}

ALT - alanine aminotransferase; AST - aspartate aminotransferase; ALP - alkaline phosphatase; LDH - lactate dehydrogenase; CK creatine kinase; Alb - albumin; BUN - blood urea nitrogen; Glu - glucose; TG - triglycerides; Ca - calcium. Values are mean \pm SD of seven rats in each group. $* \mathrm{P}<0.05 ; * * \mathrm{P}<0.01$

FLU decreased total serum bilirubin in a dosedependent manner. Administration of $750 \mathrm{mg} / \mathrm{kg}$ of FLU significantly raised the levels of inorganic phosphate, total cholesterol (TC), low density lipoprotein (LDL), and high density lipoprotein (HDL) compared to the corresponding levels in the controls (Fig. 3).

Preputial time and sperm parameters. The sperm motility parameters, sperm counts and the 
preputial time did not show any significant differences between control and FLU-treated rats (Table 3).

Immunoglobulin and blood cytokines. IgG and IgE were significantly $(\mathrm{P}<0.05)$ less concentrated in serum after treatment with FLU 750 compared to controls (Fig. 4). IL-10, IL-6, TNF- $\alpha$, and IFN- $\gamma$ were at significantly $(\mathrm{P}<0.05)$ lower levels in the FLU 200 and 750 groups. The levels of IL-2, GM-CSF and IL-1 $\beta$ did not change with any statistical significance (Fig. 5).
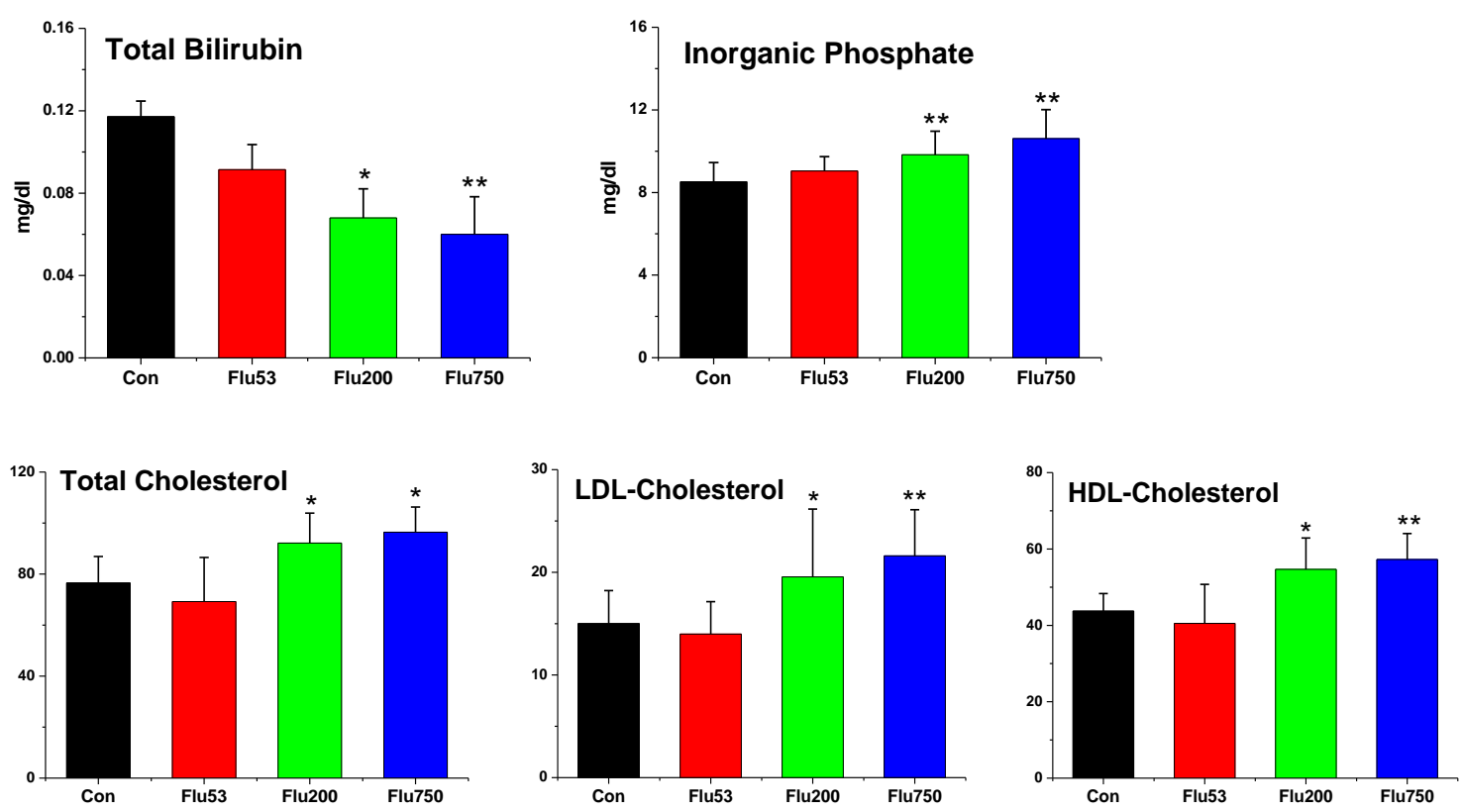

Fig. 3. Serum biochemical parameters of pubertal male Wistar rats treated with corn oil (control) or flumequine (FLU) for six weeks Values are mean $\pm \mathrm{SD}$ of seven rats in each group. $* \mathrm{P}<0.05 ; * * \mathrm{P}<0.01$

Table 3. Sperm motility parameters, sperm numbers, and preputial time of pubertal male Wistar rats exposed to FLU for six weeks

\begin{tabular}{lllll}
\hline Parameter & Corn oil & $53 \mathrm{mg} / \mathrm{kg}$ & $200 \mathrm{mg} / \mathrm{kg}$ & $750 \mathrm{mg} / \mathrm{kg}$ \\
\hline Motility $(\%)$ & $73.84 \pm 18.89$ & $75.21 \pm 7.62$ & $67.38 \pm 17.19$ & $75.1 \pm 10.98$ \\
HYP $(\%)$ & $34.85 \pm 11.11$ & $33.08 \pm 11.04$ & $39.4 \pm 9.41$ & $38.69 \pm 15.38$ \\
VCL $(\mathrm{m} / \mathrm{s})$ & $114.5 \pm 15.46$ & $98.84 \pm 33$ & $97.62 \pm 24.97$ & $116.7 \pm 26.85$ \\
VSL $(\mathrm{m} / \mathrm{s})$ & $49.56 \pm 22.86$ & $42.48 \pm 25.36$ & $29.96 \pm 26.22$ & $43.73 \pm 28.57$ \\
VAP $(\mathrm{m} / \mathrm{s})$ & $65.62 \pm 20.37$ & $53.06 \pm 28.43$ & $47.12 \pm 23.86$ & $65.53 \pm 27.4$ \\
LIN & $42.14 \pm 14.8$ & $32.16 \pm 16.43$ & $27.47 \pm 19.59$ & $39.84 \pm 17.03$ \\
STR & $72.73 \pm 12.25$ & $59.82 \pm 18.36$ & $53.54 \pm 27.14$ & $70.76 \pm 16.49$ \\
BCF $(\mathrm{Hz})$ & $11.22 \pm 1.148$ & $10.64 \pm 2.02$ & $10.4 \pm 1.63$ & $11.05 \pm 1.09$ \\
MAD $($ degree $)$ & $4.85 \pm 1.9$ & $4.05 \pm 1.8$ & $3.35 \pm 1.82$ & $4.21 \pm 2.07$ \\
WOB & $56.3 \pm 10.95$ & $48.6 \pm 14.12$ & $46.77 \pm 12.18$ & $54.26 \pm 12.15$ \\
DNC & $1152.16 \pm 185.66$ & $1081.74 \pm 387.94$ & $966.36 \pm 359.05$ & $1263.49 \pm 416.64$ \\
DNM $(\mu \mathrm{m})$ & $27.59 \pm 12.16$ & $39.65 \pm 17.03$ & $30.22 \pm 9.39$ & $32.79 \pm 16.04$ \\
ALH $(\mu \mathrm{m})$ & $10.03 \pm 0.76$ & $9.40 \pm 1.81$ & $9.35 \pm 1.54$ & $10.56 \pm 1.521$ \\
Sperm numbers $\left(\times 10^{4}\right)^{+}$ & $38 \pm 9$ & $48 \pm 10$ & $44 \pm 8$ & $35 \pm 9$ \\
Preputial time $($ days $)$ & $40 \pm 1.5$ & $39 \pm 1.2$ & $39 \pm 1.8$ & $40 \pm 1$ \\
\hline
\end{tabular}

Rats were administered orally with FLU $(53,200,750 \mathrm{mg} / \mathrm{kg})$ for 6 weeks. Values are mean \pm SD of seven rats in each group. Sperm numbers were determined at cauda eipididymis and represented as $\times 10^{4} / \mathrm{g}$.

HYP - hyperactive cell percentage; VCL - curvilinear velocity; VSL - straight line velocity; VAP - average path velocity; LIN - linearity; STR - straightness; BCF - beat cross frequency; MAD - mean angular displacement; WOB - wobble coefficient; DNC - dance; DNM mean dance; ALH - amplitude of lateral head displacement 

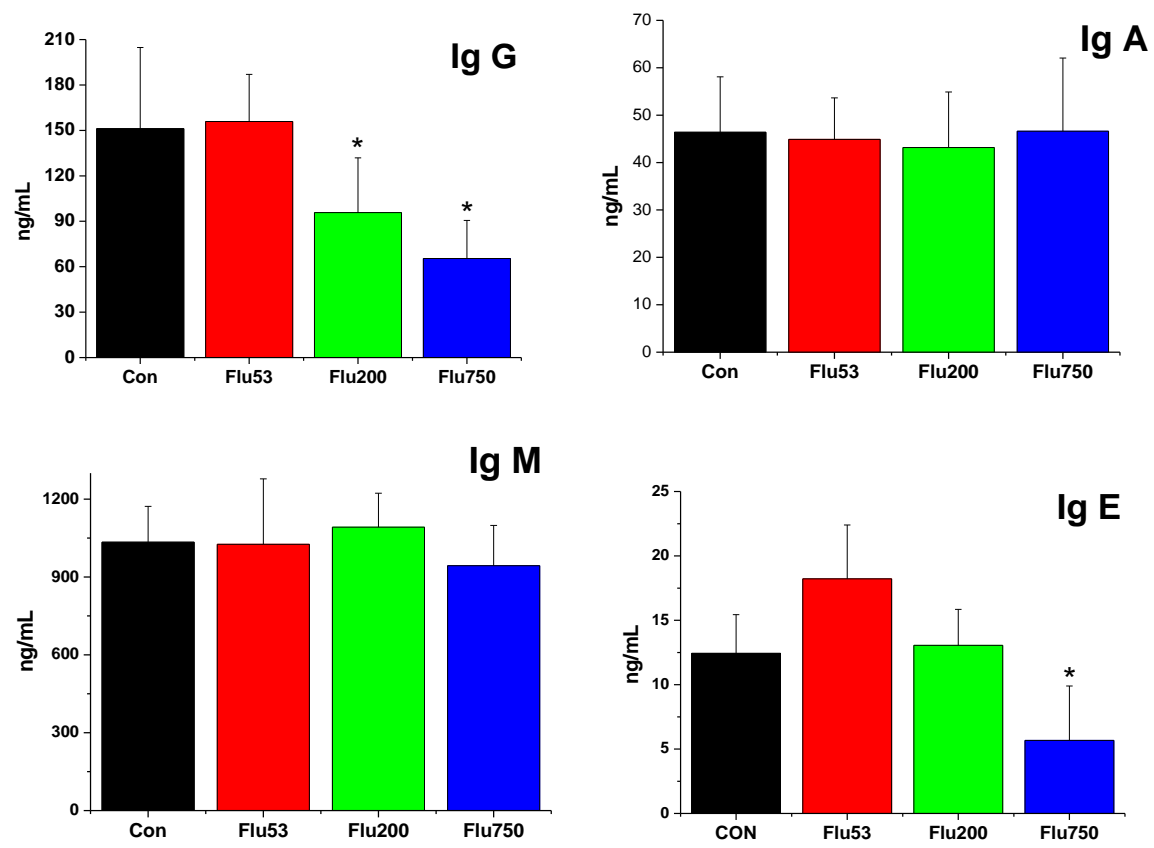

Fig. 4. Changes in serum immunoglobulins in Wistar male rats of control group and flumequine (FLU) 53,200 , and 750 groups. Values are mean $\pm \mathrm{SD}$ of seven rats in each group. $* \mathrm{P}<0.05 ; * * \mathrm{P}<0.01$
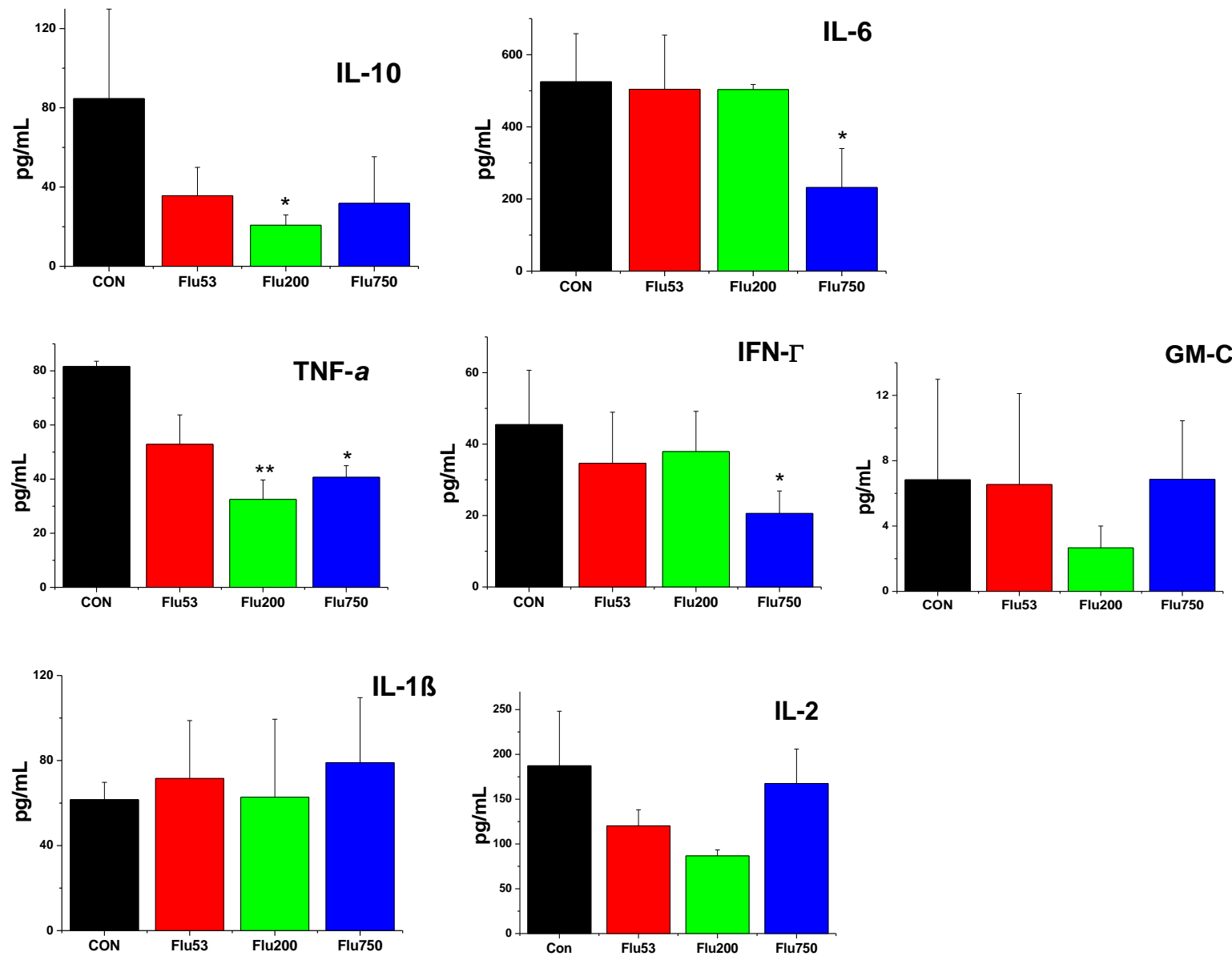

Fig. 5. Changes in plasma cytokines in Wistar male rats treated with corn oil (control) or flumequine (FLU) 53, 200, and $750 \mathrm{mg} / \mathrm{kg}$ for six weeks.

IL-10 - interleukin-10; IL-6 - interleukin-6; TNF- $\alpha$ - tumour necrosis factor- $\alpha$; IFN- $\gamma$ - interferon- $\gamma$; GM-CSF - granulocyte-macrophage colony-stimulating factor; IL-1 $\beta$ - interleukin-1 $\beta$; IL-2 - interleukin-2. Values are mean \pm SD for seven rats in each group. * $\mathrm{P}<0.05$; $* * \mathrm{P}<0.01$ 

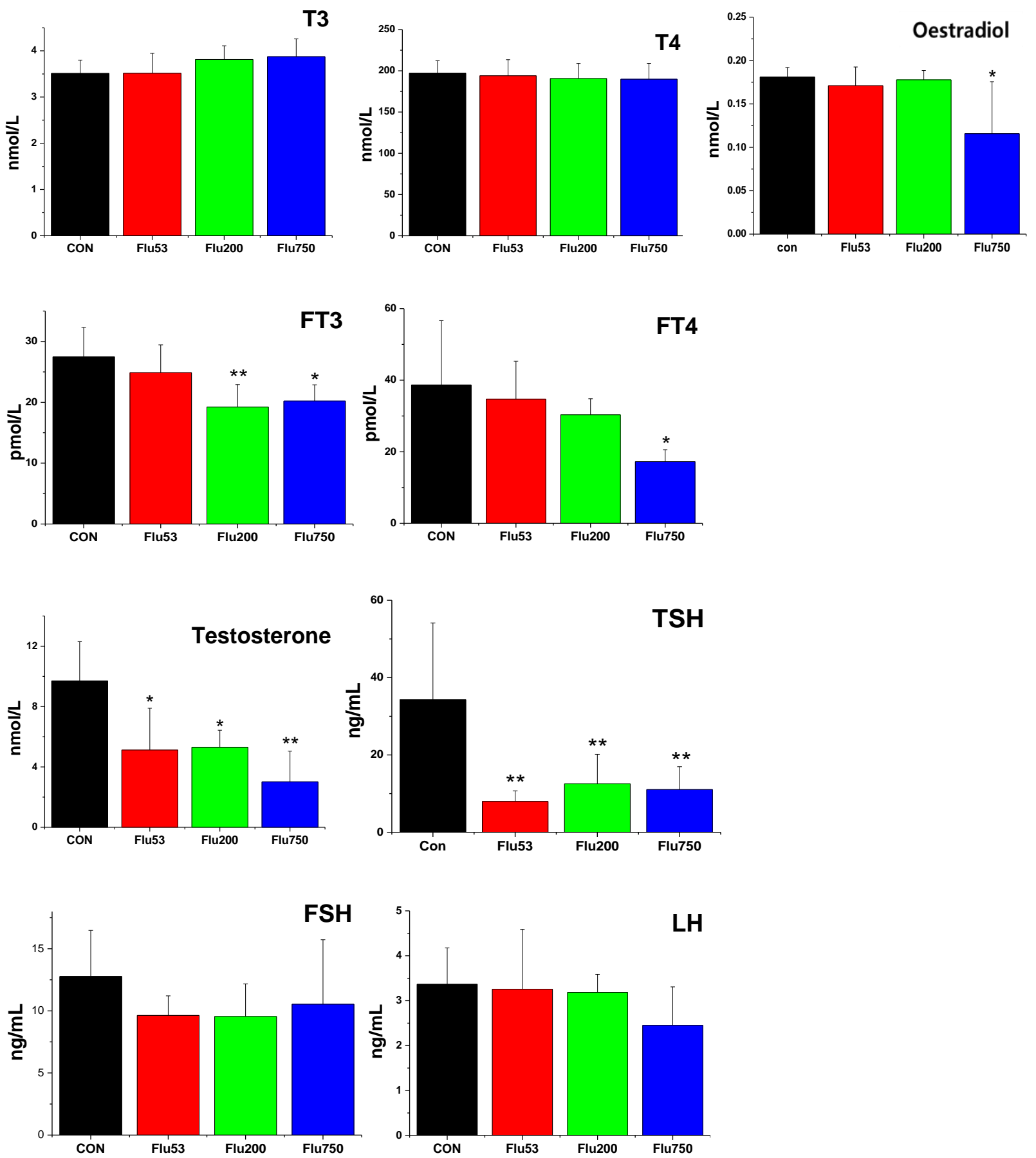

Fig. 6. Changes in serum hormones in Wistar male rats treated with corn oil (control) or flumequine (FLU) 53, 200, and 750 mg/kg for six weeks TSH - thyroid stimulating hormone; FSH - follicle stimulating hormone; LH - luteinising hormone; fT4 - free T4; fT3 - free T3; tT4 - total thyroxine; tT3 - total triiodothyronine. Values are mean \pm SD for seven rats in each group $* \mathrm{P}<0.05 ; * * \mathrm{P}<0.01$

Serum hormone levels. The serum levels of fT3 and fT4 were significantly decreased by the treatment with FLU 200 or $750 \mathrm{mg} / \mathrm{kg}$ compared to the control group, without changes in total T3 and T4 levels. The levels of thyroid stimulating hormone (TSH) and testosterone were significantly $(\mathrm{P}<0.05)$ decreased after all doses of FLU, and the level of oestradiol was significantly decreased $(\mathrm{P}<0.05)$ after treatment with FLU 750 only. Serum FSH and LH were not affected by the treatment with FLU (Fig. 6).
Histopathological changes and expression of toxicity-related protein markers. The thyroid glands of rats treated with FLU 750 showed degeneration and depletion of thyroid follicular epithelial cells compared to the thyroid glands in the control (Fig. 7). Other organs (brain, thymus, lungs, liver, kidneys, adrenal glands, testes, epididymis, and prostate glands) were found to be within normal limits. Expression of 8 -OHdG was significantly increased $(\mathrm{P}<0.01)$ in a dose-dependent manner in the brain, but was 
decreased in the testes after the $750 \mathrm{mg} / \mathrm{kg}$ dose. In the liver, expression of 8-OHdG was found to be increased, but the change was not statistically significant. CYP1A1 expression increased in the adrenal and pituitary glands. Cox-2 expression increased in the spleen and brain after treatment with FLU. IL-1 $\beta$ expression increased in the spleen but decreased in the brain after FLU treatment (Fig. 8).
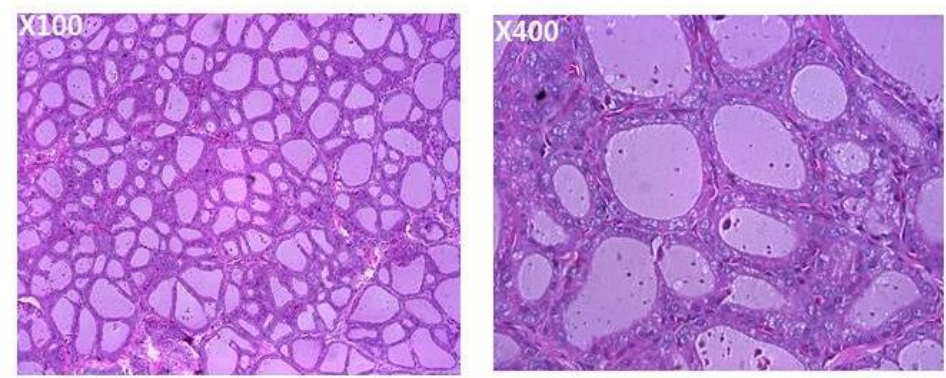

Corn oil (control)
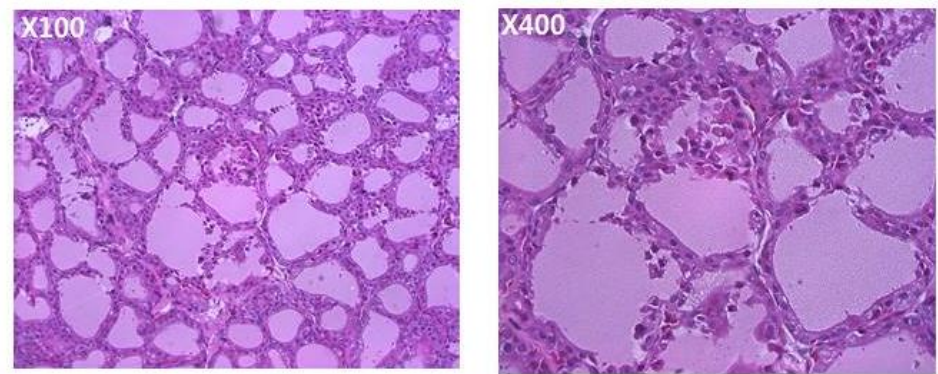

Flu 750

Fig. 7. Histopathological findings in thyroid glands from Wistar male rats treated with corn oil (control) or flumequine (FLU) in a dose of $750 \mathrm{mg} / \mathrm{kg}$ for six weeks. Degeneration and depletion of thyroid follicular epithelial cells are present
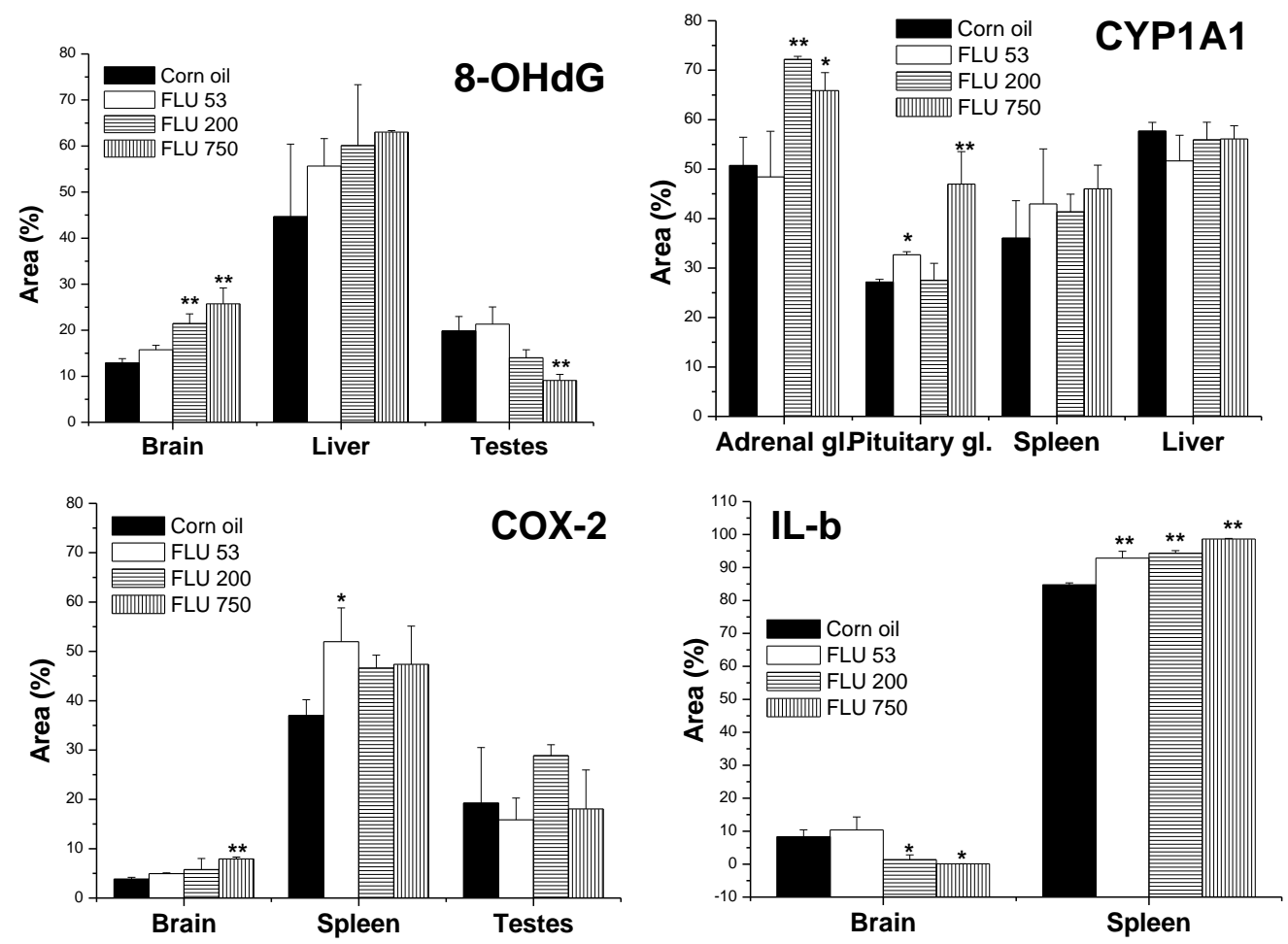

Fig. 8. Expression of 8-hydroxydeoxyguanosine (8-OHdG), cytochrome P450, family 1, subfamily A, polypeptide 1 (CYP1A1), cyclooxygenase-2 (COX-2) and interleukin-1 $\beta$ (IL-1 $\beta$ ) in Wistar male rats treated with corn oil (control), or flumequine (FLU) in a dose of 53,200 , and $750 \mathrm{mg} / \mathrm{kg}$ for six weeks. Values are mean $\pm \mathrm{SD}$ of seven rats in each group. $* \mathrm{P}<0.05 ; * * \mathrm{P}<0.01$ 


\section{Discussion}

The Joint FAO/WHO Expert Committee on Food Additives (JECFA) classified FLU as a non-genotoxic carcinogen since it induced hepatic tumours in mice after chronic oral administration, but was negative in mutation tests (Ames test, the hypoxanthine phosphoribosyl transferase test, and gene mutation and chromosomal aberration assays) (11). Few studies have been conducted to assess the toxicity of FLU in pubertal male rats after long-term exposure. In the present study, FLU was administered to four-week-old male rats for six weeks. Increased absolute or relative kidney weight can be used as a sensitive indicator of kidney toxicity (14). If body weight is reduced in a toxicity study, changes in the relative organ weights (organ weight/body weight ratio) are the more appropriate measure of pathophysiological response (18). The present study showed that the adrenal glands, brain, thyroid glands, and testes are the major target organs for FLU toxicity based on changes in relative organ weights. FLU showed no effect on liver weight, which was the suspected major target organ in mice. Histopathological observation also showed degeneration and depletion of follicular epithelial cells in the thyroid. Although absolute weights of epididymis, thymus, and prostate glands fell, these effects were likely due to the fall in body weight. These findings showed that the thyroid glands were the most sensitive organ to FLU toxicity because the relative weight rose after the two highest doses of FLU (200 and $750 \mathrm{mg} / \mathrm{kg}$ ) and occurrence of histopathological changes.

The haematological results in the present study showed that the WBC, $\mathrm{MCH}, \mathrm{MO}$, and $\mathrm{CH}$ increased after FLU treatment in a dose of $750 \mathrm{mg} / \mathrm{kg}$. A WBC count can be higher due to inflammation and immune stimulation. Monocyte proliferation is triggered to destroy non-sensitised target cells by immune complexes through activation of nonspecific cytotoxic mechanisms $(7,9)$. The present study indicated that a high dose of FLU may effect damage at tissue or cellular level which is followed by an increase in the number of nonspecific immune cells like monocytes. The high dose of FLU also augmented CK and LDH activity, which may have been induced by the tissue or cell damage. Although FLU 200 did not increase CK and LDH activity in this study, it may produce damage at the tissue or cellular level.

Cholesterol levels have been found to be inversely related to the level of thyroid hormone in blood (2). Increased thyroid function lowered blood cholesterol levels (16). In the present study, the relative thyroid gland weight was increased by FLU 200 and 750 as there co-occurred a reduction of free thyroid hormones and increase in blood cholesterol. Our study supports the inverse relationship between cholesterol levels and thyroid hormone levels in blood. In the present study, the relative weight of testes increased and the serum level of testosterone decreased. It has been reported that the inhibition of androgen pathways in the testes could result from the increase in adrenal gland weight due to compensatory activation (12). An increase in testis weight might be a compensatory mechanism due to the decrease in serum testosterone caused by FLU treatment. In the present study, FLU affected the endocrine system in male Wistar rats as is evident by the decreased pituitary-thyroid axis hormones fT3, fT4, and TSH. Sperm motility and preputial separation time showed no differences between control and treatment groups, but oestradiol and testosterone decreased in rats treated with FLU. It has been reported that an inducer of CYP1A1 may bind to androgen receptors and act as an anti-androgen, which would decrease thyroxine and TSH levels (17). In this study, we showed that CYP1A1 expression was increased in the adrenal glands, which are also a source of androgens. FLU treatment produced degeneration and depletion of follicular epithelial cells of the thyroid thus decreasing fT3 and fT4 in blood. These findings also support that the thyroid gland could be a major target tissue for FLU toxicity as shown by the pathological lesions. These data suggest that FLU might be an endocrine disruptor in the androgen and thyroid systems. Additional studies are required to elucidate the exact endocrine disruptive mechanism of FLU in male rats.

The expression of $8-\mathrm{OHdG}$ was chosen as a marker for oxidative damage and stress, that of CYP1A1 was adopted as a marker of cell proliferation, COX-2 as a marker of inflammation, and IL-1 $\beta$ as a marker of immune function. FLU treatment induced the expression of $8-\mathrm{OHdG}$ in the liver of CD-1 mice after oral administration for 18 months in a previous study (21). The effect of FLU in the expression of 8-OHdG may be related to the carcinogenesis in the liver. It was found in the present study that the expression of 8-OHdG intensified in brain tissue and it showed a tendency to increase in the liver. This difference in expression of $8-\mathrm{OHdG}$ in the liver between CD-1 mice and Wistar rats might be due to the difference in species and the length of exposure to FLU. Our data also suggest that FLU may cause oxidative damage in brain tissue. CYP1A1 is an enzyme involved in phase 1 of xenobiotic and drug metabolism. The sustained induction of this enzyme may be related to the carcinogenic effect of polyaromatic hydrocarbon compounds (6). In the present study, adrenal and pituitary glands were target tissues that showed increased expression of CYP1A1. In the adrenal glands, the increase in expression was observed at those same doses of FLU (200 and $750 \mathrm{mg} / \mathrm{kg}$ ) which increased organ weight. There was no difference in expression of CYP1A1 in the liver after FLU administration. Our experiment data suggest that adrenal glands may also be a target of FLU toxicity as evident by increased organ weight and expression of CYP1A1 in the adrenals.

COX-2 plays a prominent role in inflammation. COX-2 derived prostaglandins upregulated the expression of COX-2 and IL-6 at inflammatory sites 
(3). The inhibition of COX-2 down-regulated the expressions of IL- 6 , IFN- $\gamma$, IL- $1 \beta$, and TNF- $\alpha$ (5). IL-10 acts as an enhancer for the cytolytic activity of T cells and proliferation of B cells. IL-6 increases immunoglobulin secretion from $\mathrm{B}$ cells and synergises with IL-4 to increase secretion of IgE. TNF- $\alpha$ induces the secretion of inflammatory cytokines and IFN- $\gamma$ activates macrophages. The spleen is an indispensable immune organ involved in humoral immunity and produces cytokines and antibodies. In the present study, the expressions of COX-2 and IL- $1 \beta$ rose in the spleen after FLU treatment, but levels of cytokines and blood $\mathrm{IgG}$ and IgE fell at the same time. The serum levels of IL-10, IL-6, TNF- $\alpha$, and IFN- $\gamma$ were reduced along with the reduction of $\mathrm{IgG}$ and $\mathrm{IgE}$.

In conclusion, the toxic effects of FLU in rats are tightly linked with the toxicity on thyroid and pituitary hormonal systems. Oxidative stress as well as the dysfunction of the immune system may also contribute to the total toxic effects of FLU.

Conflict of Interests Statement: The authors declare that there is no conflict of interests regarding the publication of this article.

Financial Disclosure Statement: This work was supported by a grant (6234-300-210-13) from the Animal and Plant Quarantine Agency, Ministry of Agriculture, Food, and Rural Affairs, Republic of Korea.

Animal Rights Statement: The experiment was carried out with the approval of the Ethical Committee of Animal and Plant Quarantine Agency, Republic of Korea.

\section{References}

1. Aller-Moran L.M., Martinez-Lobo F.J., Rubio P., Carvajal A.: Evaluation of the in vitro activity of flumequine against field isolates of Brachyspira hyodysenteriae. Res Vet Sci 2015, 103, 51-53.

2. Angela L.: Thyroid and Cholesterol: Does thyroid stimulating hormone (TSH) affect cholesterol levels? Clin Thyroidol 2012, 5, 3. https://www.thyroid.org/wp-content/uploads/publications/ ctfp/volume5/issue12/ct_patients_v512_3.pdf.

3. Cheng L., Ming-liang H., Lars B.: Is COX-2 a perpetrator or a protector? Selective COX-2 inhibitors remain controversial. Acta Pharm Sin 2005, 26, 926-933.

4. Cho J.H., Jeong S.H., Ku H.O., Kang H.G., Park J.M., Yun H.I., Lee Y.S.: Improved novel method of blood sample collection via jugular vein in unanaesthetized rats. Korean J Lab Anim Sci 1997, 13, 117-120.

5. Cruz R., Quintana-Hau J.D., Gonzalez J.R., Tornero-Montano R., Baiza-Duran L.M., Vega L.: Effects of an ophthalmic formulation of meloxicam on COX-2 expression, PGE2 release, and cytokine expression in a model of acute ocular inflammation. Br J Ophthalmol 2008, 92, 120-125.

6. Fazili I.S., Jiang W., Wang L., Felix E.A., Khatlani T., Coumoul X., Barouki R., Moorthy B.: Persistent induction of cytochrome P4501A1 in human hepatoma cells by 3-methylcholanthrene: evidence for sustained transcriptional activation of the CYP1A1 promoter. J Pharmacol Exp Ther 2010, 333, 99-109.

7. Geffner J.R., Minnucci F., Isturiz M.A.: Interferon-gamma is unable to increase monocyte and neutrophil-mediated nonspecific cytotoxicity induced by immune complexes. Immunol Lett 1992, 33, 21-25.

8. Groelz D., Sobin L., Branton P., Compton C., Wyrich R., Rainen L.: Non-formalin fixative versus formalin-fixed tissue: A comparison of histology and RNA quality. Exp Mol Pathol 2013, 94, 188-194.

9. Jensen H.S., Mogensen H.H., Kjaersgaard E.: Blood monocyte elastolytic activity enhanced by immune complex stimulation in patients with rheumatoid arthritis and normal controls. Effect of aurothiomalate or D-penicillamine. Scand J Rheumatol 1989, 18, 297-305.

10. Jeong S.H., Kim B.Y., Kang H.G., Ku H.O., Cho J.H.: Effects of butylated hydroxyanisole on the development and functions of reproductive system in rats. Toxicology 2005, 208, 49-62.

11. Joint FAO/WHO Expert Committee on Food Additives (JECFA): Toxicological evaluation of certain veterinary drug residues in food. World Health Organization, Geneva, Switzerland, 2004 WHO Food Additives Series: 51.

12. Kang H.G., Jeong S.H., Cho J.H., Kim D.G., Park J.M., Cho M.H.: Chlropyrifos-methyl shows anti-androgenic activity without estrogenic activity in rats. Toxicology 2004, 199, 219-230.

13. Kuroda K., Kijima A., Ishii Y., Takasu S., Jin M., Matsushita K., Kodama Y., Umemura T.: Flumequine enhances the in vivo mutagenicity of MeIQx in the mouse liver. Arch Toxicol 2013, 87, 1609-1619.

14. Lopez-Giacoman S., Madero M.: Biomarkers in chronic kidney disease, from kidney function to kidney damage. World J Nephrol 2015, 4, 57-73.

15. OECD/OCDE. OECD guideline for the testing of chemicals Repeated dose 90-days oral toxicity study in rodents, 1998 p. 408.

16. Rizos C.V., Elisaf M.S., Liberopoulos E.N.: Effects of thyroid dysfunction on lipid profile. Open Cardiovasc Med J 2011, 5, 76-84.

17. Sanderson J.T.: The Steroid Hormone Biosynthesis Pathway as a Target for Endocrine-Disrupting Chemicals. Toxicol Sci 2006, 94, 3-21.

18. Scharer K.: The effect of chronic underfeeding on organ weights of rats. How to interpret organ weight changes in cases of marked growth retardation in toxicity tests? Toxicology 1977, 7 , $45-56$.

19. Summary report (2) flumequine (EMEA/MRL/624/99-FINAL), Committee for veterinary medicinal products, the European Agency for the Evaluation of Medicinal Products. 1999.

20. Van der Heijden M.H., Booms G.H., Tanck M.W., Rombout J.H., Boon J.H.: Influence of flumequine on in vivo mitogen responses of European eel (Anguilla anguilla L., 1758) lymphoid cells. Vet Immunol Immunopathol 1995, 47, 143-152.

21. Yoshida M., Miyajima K., Shiraki K., AndoK K.J., Nakae D., Takahashi M., Maekawa A.: Hepatotoxicity and consequently increased cell proliferation are associated with flumequine hepatocarcinogenesis in mice. Cancer Lett 1999, 141, 99-107. 